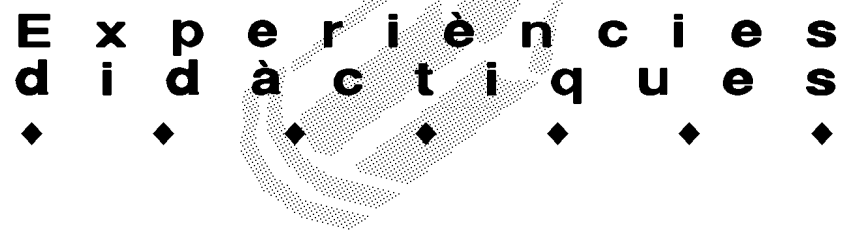

\title{
JOC I MATEMÀTIQUES: RECERCA I IMPLICACIONS DIDÀCTIQUES
}

\author{
Mequè Edo i Basté. Àrea de Didàctica de la Matemàtica. Universitat Autònoma de Barcelona
}

\section{Introducció}

La recerca de la millora de l'ensenyament i aprenentatge de les matemàtiques escolars condueix a l'estudi de situacions didàctiques concretes que poden ser referents de bones pràctiques. Seguint Van Oers $(1994,2003)$, considerem que les bones pràctiques escolars són aquelles que cerquen un aprenentatge efectiu, és a dir, aquelles que tenen en consideració tant l'augment de les capacitats cognitives dels alumnes com la millora de les habilitats i capacitats de relació social per participar efectivament en la vida sociocultural de la comunitat. En el nostre cas, entenem que alguns jocs ben utilitzats a l'escola poden crear un context proper a una bona pràctica. Poden ajudar a l'aprenentatge de diferents continguts matemàtics curriculars i incidir positivament en el desenvolupament personal i social dels alumnes.

\section{Joc, aprenentatge i desenvolupament}

La importància del joc infantil ha estat estudiada àmpliament per diferents autors al llarg del darrer segle. Assumim l'existència d'una relació important entre el joc, l'aprenentatge i el desenvolupament (PIAGET, 1986; VAN OERS 1994, 1999; VYGOTSKI, 2003; entre altres). Aquesta relació es vincula amb la creació de situacions imaginàries $\mathrm{i}$ amb la participació voluntària en una activitat subjecta a regles (VYGOTSKI, op. cit.). Un dels acords generals entre els diferents autors és que en el joc és més important el procés que el producte final. Aquest valor del procés es vincula amb els possibles aprenentatges personals i socials que poden produir-se en el context de joc.

En aquest punt entenem el joc com "una activitat voluntària caracteritzada per unes regles públiques i per alguns graus de llibertat d'elecció dels actors involucrats" (VAN OERS, 1999. Pàg. 269).

Diferents autors (els citats fins ara; BELMONTE, 2006; GARAIGORDOBIL, 2005; ORTEGA 1991) han estudiat l'evolució natural del joc en la infància, del qual remarquem tres grans categories:

1) El joc exploratori o manipulatiu. És el joc que permet a l'infant explorar i fer seu el món que l'envolta, allò que té ara i aquí. Se centra en qüestions com: Què és això? Com és això? Què puc fer amb això? És una activitat característica dels primers anys de vida, però reapareix al Ilarg de l'escolaritat obligatòria en cada ocasió en què es presenta un material manipulatiu desconegut.

2) El joc simbòlic o d'imitació. És el que apareix quan als objectes se'ls assignen característiques i propietats diferents de les de la realitat. Se centra en qüestions com: Això és com si fos un...; jo faig com si fos...; això ara és... Aquest joc comença en el moment que l'infant desenvolupa la capacitat d'evocar objectes o accions absents. És una activitat característica entre els tres i els set anys, però continua tenint sentit al llarg de l'educació primària en organitzar situacions de joc de simulació d'entorns reals que volem conèixer i estudiar, com ara una botiga de queviures, un poblat de la prehistòria, un taller de fusteria, una agència de viatges, etc.

3) El joc de regles o de societat. Activitat on les accions i eleccions dels jugadors estan regides per unes regles concretes, públiques i lliurement acceptades i hi ha algun objectiu que s'ha d'assolir. Se centra en qüestions com: Què puc fer per assolir l'objectiu? Què puc fer perquè l'altre no l'assoleixi abans que jo? És una activitat que porta implícites la socialització i la competició. Apareix a partir dels quatre anys, pren gran importància a partir dels sis anys i genera un interès que pot continuar durant tota la vida.

Aquesta relació no pretén ser exhaustiva, sinó mostrar a grans trets les tres grans categories de joc que apareixen de forma natural durant el desenvolupament humà.

Podem observar que, malgrat l'aparició natural a la infància d'aquests tipus de joc, es produeix de forma gradual i seqüencial, ja que en el marc escolar no desapareix del tot l'interès pel joc anterior en afegir-ne un de nou. $\mathrm{Hi}$ ha autors com Van Oers $(1994,1999)$ que defensen l'existència d'unes activitats concretes conductores de l'aprenentatge en cada etapa del desenvolupament infantil, és a dir, activitats especialment adequades -encara que no exclusives- per a cada edat.

Els resultats de les recerques d'aquest autor, inspirades en Vygotski (op. cit.) i Elkonin (1980), proposen que l'activitat natural conductora de l'aprenentatge des dels quatre als set anys és el joc simbòlic, i a partir dels set 


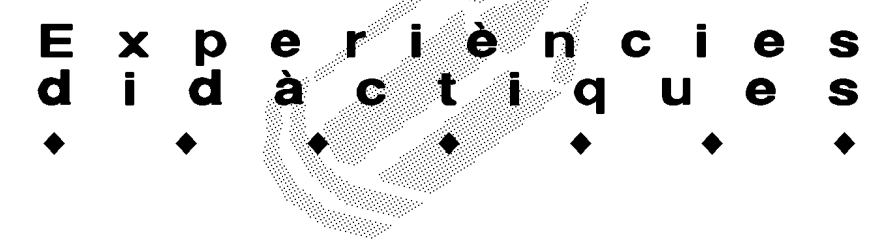

anys esdevé l'activitat d'aprenentatge conscient (per conèixer una experiència d'anàlisi d'aprenentatges matemàtics en un context de joc simbòlic, vegeu Edo i Masoliver, 2008). El mateix autor proposa utilitzar en el context escolar, tant a educació infantil com a primària, diferents tipus de jocs per afavorir diferents tipus d'aprenentatge (cognitius, socials, morals...).

\section{Joc i matemàtiques}

Bishop (1999) conclou, a partir de recerques antropològiques amb diferents grups culturals, que hi ha sis activitats culturals universals vinculades a la matemàtica: comptar, localitzar, mesurar, dissenyar, jugar i explicar. Nosaltres, com l'autor, considerem que jugar incideix positivament en el desenvolupament del pensament matemàtic.

Creiem que caldria seguir les recomanacions d'informes internacionals sobre la utilització de jocs i activitats lúdiques en l'educació matemàtica escolar (COCKCROFT, 1985; NCTM, 2000). De fet, en el currículum de matemàtiques actual de l'educació obligatòria a Catalunya (GENERALITAT CATALUNYA, 2007) apareixen referències concretes sobre la utilització dels jocs per a l'aprenentatge de les matemàtiques a primària. Quan parla sobre les consideracions per al desenvolupament del currículum, diu: "Cal que els continguts curriculars es treballin en contextos significatius i rics com [...] les situacions quotidianes, [...] però també els jocs i les pròpies matemàtiques, i en particular la seva història, han de ser les fonts que ens proporcionin els contextos més rellevants per aprendre matemàtiques".

Avui existeixen recerques amb resultats força coincidents sobre la relació positiva de la utilització de jocs de regles o de societat i aprenentatges matemàtics, especialment relacionats amb aspectes numèrics, aritmètics i lògics. En aquest sentit remarquem els treballs de Desjardins-Royon (1991); Kamii (1988, 1992); Kamii i de Vries (1980); Kamii i Kato (2005); Kamii, Rummelsburg i Kari (2005). Però també hi ha resultats de recerca que evidencien que uns determinats contextos de joc potencien l'augment de l'autoestima i l'augment de l'ús del llenguatge matemàtic: Topping i Bamford (1998); Topping, Campbell, Douglas i Smith (2003).

Retornant a la idea de la bona pràctica, presentada a la introducció, entenem que el valor del joc dins l'escola no es troba exclusivament en l'augment de les capacitats cognitives (numèriques, aritmètiques o lògiques) dels nostres alumnes. El valor afegit és com es produeix aquest augment i en quin tipus d'estructura de participació social es dóna.

- L'ambient, el clima distès, relaxat i lúdic, on l'error forma part natural del procés i no s'interpreta com "haver fallat", és clau.
- Les emocions que es poden viure durant el joc i durant l'aprenentatge queden registrades i són diferents de les que es poden sentir en aprendre a través d'exercicis escrits.

- La dinàmica social afavoreix que els mestres puguin realitzar un suport inicial alt, (BRUNER, 1985), i amb el temps cedeixin i traspassin el control i la gestió de la tasca als mateixos alumnes.

- La mateixa dinàmica pot afavorir que els alumnes augmentin la capacitat de col-laboració i cooperació, i la capacitat de donar-se suport en el mateix procés d'aprenentatge.

Sembla, doncs, que la clau diferencial del que aporta l'aprenentatge que es produeix en un context de joc és en els "altres", és a dir, en les relacions socials que creen els entorns de joc, que són, com hem dit amb els jocs de regles, competitius però alhora i necessàriament cooperatius i col-laboratius.

\section{Descripció general de la recerca}

Ja fa uns anys que un grup de professors de la Universitat Autònoma de Barcelona vam centrar la recerca en aquest camp. Per totes les raons que s'han exposat fins ara i amb la voluntat d'aconseguir evidències que ens permetessin respondre millor sobre si el joc, en el marc escolar, es podia considerar una bona pràctica per a l'ensenyament i aprenentage de les matemàtiques, i si fos el cas, poder mostrar per què ho era, vam dissenyar una recerca situada en un entorn de joc a l'àrea de matemàtiques al cicle inicial de primària. Aquest estudi es va realitzar en dues fases.

La primera fase es va centrar en el disseny, implementació i avaluació d'un taller de jocs de taula i matemàtiques al cicle inicial de primària. Un dels principals resultats d'aquesta fase, que s'exposarà més endavant, se centra en l'estudi de l'augment de la capacitat dels alumnes de calcular mentalment, gràcies a aquest taller.

Ja des del començament crèiem que la importància de l'aprenentatge que es realitza en el context de joc es troba en els "altres". Ens interessava estudiar "què" s'aprenia, però també "com" s'aprenia, i ens sentíem inclinats a investigar si es produïa un augment de la cooperació i col-laboració entre alumnes en aquest marc. Ens preguntàvem si en un context de joc col-lectiu, malgrat la competitivitat natural de l'activitat, s'aprenia realment "amb" i "dels" altres. Enteníem que el bon funcionament de qualsevol activitat de joc col-lectiu requeria la participació activa i col-laborativa de tots els jugadors. Per tot això, ens vam plantejar trobar les evidències per les quals els alumnes exercien influència educativa en la seva interacció entre iguals en un context de joc de taula i matemàtiques, és a dir, observar si augmentava la capacitat de realització d'ajudes mútues en els processos d'apre- 


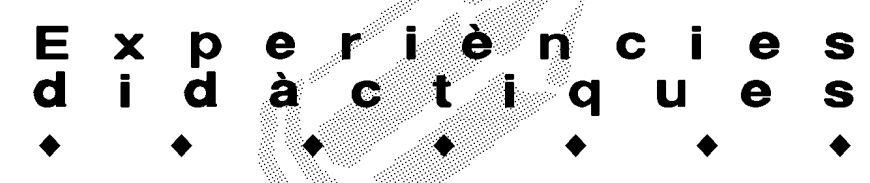

nentatges matemàtics. La segona fase de la recerca, que es va realitzar amb les dades enregistrades i transcrites de dues seqüències didàctiques del taller, es va centrar en l'estudi de les interaccions dels participants.

\section{Disseny, aplicació i avaluació d'un taller de joc i mate- màtiques al cicle inicial de primària}

El taller de jocs i matemàtiques es va dissenyar, implementar i avaluar al CEIP Escola Bellaterra (Barcelona) el curs 1995-96. La metodologia d'aquesta fase de la investigació va ser la d'una recerca-acció (EDO, 1996). Es va formar un equip de 4 mestres de cicle inicial, 4 estudiants de mestre en pràctiques i un investigador extern. Els alumnes implicats van ser 97 nens i nenes de primer i segon curs de primària (entre sis i vuit anys). L'objectiu de l'equip va ser dissenyar un taller, d'una hora setmanal, on l'activitat dels alumnes fos realitzar algun joc de taula amb els objectius d'aprenentatge:

1. Que els alumnes fossin conscients que estaven aprenent matemàtiques en una activitat lúdica.

2. Que augmentessin les seves capacitats de calcular mentalment.

3. Que descobrissin i apliquessin estratègies de joc.

4. Que augmentessin l'autonomia i la capacitat de treball cooperatiu.

(Per a una descripció més completa de l'experiència, vegeu Edo, 1998; Costa, Edo, Font i Forrellad, 1998).
El taller complet, que en l'actualitat s'aplica a diversos centres, es compon de deu jocs, cinc per a cada curs. Tots els jocs de taula (amb cartes i daus) requereixen la realització de càlculs. Els jocs estan seqüenciats de manera que els càlculs implicats presenten dificultat creixent i cobreixen les descomposicions clau que s'han d'automatitzar en aquestes edats. Cada joc és el protagonista de quatre sessions, i cada sessió té una seqüència d'activitats recomanada: per exemple, a la primera sessió hi destaca l'explicació del joc, la conversa inicial centrada en què podrem aprendre amb aquest joc?, el temps per jugar-hi, el temps necessari per canviar de joc en cas d'acord, etc. El conjunt d'activitats varien segons la sessió (inicial, intermèdies i final). També es van definir els objectius d'aprenentatge de cada joc, els sistemes d'avaluació, la configuració dels grups d'alumnes, el paper dels adults, etc. (vegeu Edo, 2004, per a una explicació completa de les directrius i decisions del taller sencer). Vegem ara un exemple de joc.

\section{El quart joc de primer de primària és "Els tres daus"}

- Joc, ordre i nivell: "Els tres daus". Quart joc de $1 \mathrm{r}$ de primària.

- Material: Tres daus als quals la configuració de sis punts s'ha cobert amb una etiqueta blanca que estableix el valor «zero».

Un grup de cartes de l' 1 al 10 per a cada equip.

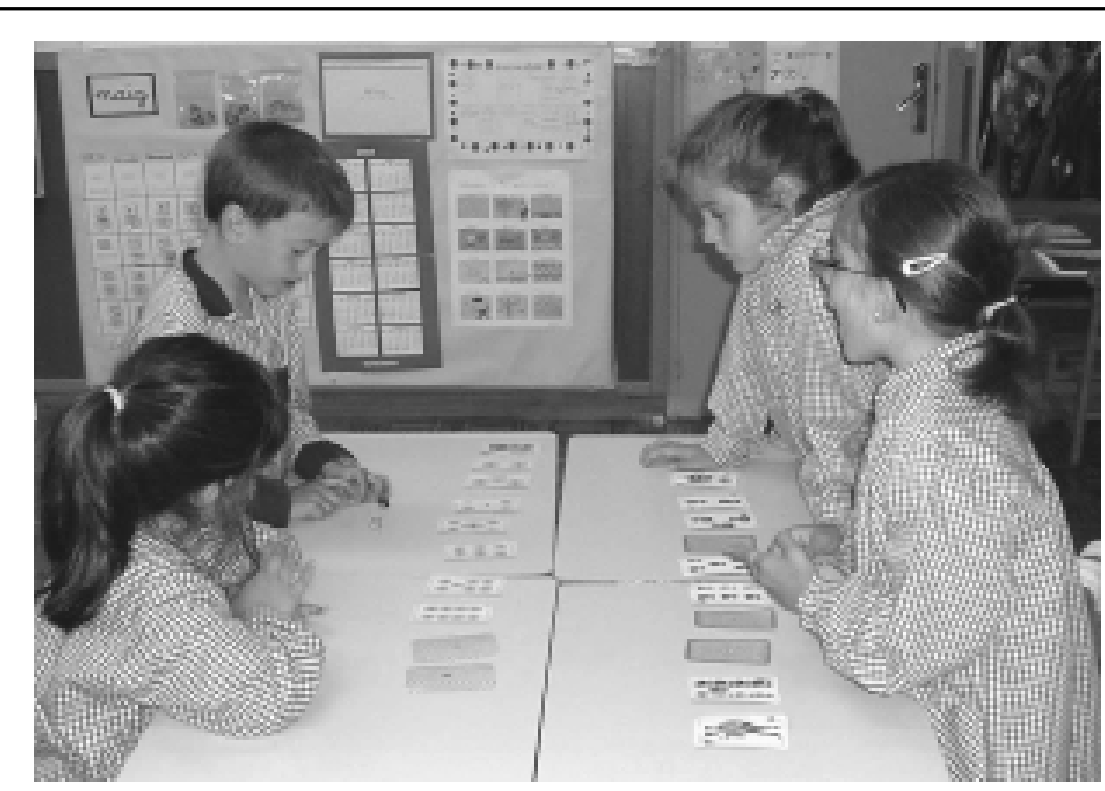

Estan jugant quatre alumnes en dos equips. Imaginem que en aquesta tirada han sortit els daus: 2,4 i 4 . Els càlculs implicats en la tirada són els que es mostren a la dreta, i les possibles cartes que s'han de girar són: 2, 4, 6, 8 i 10.

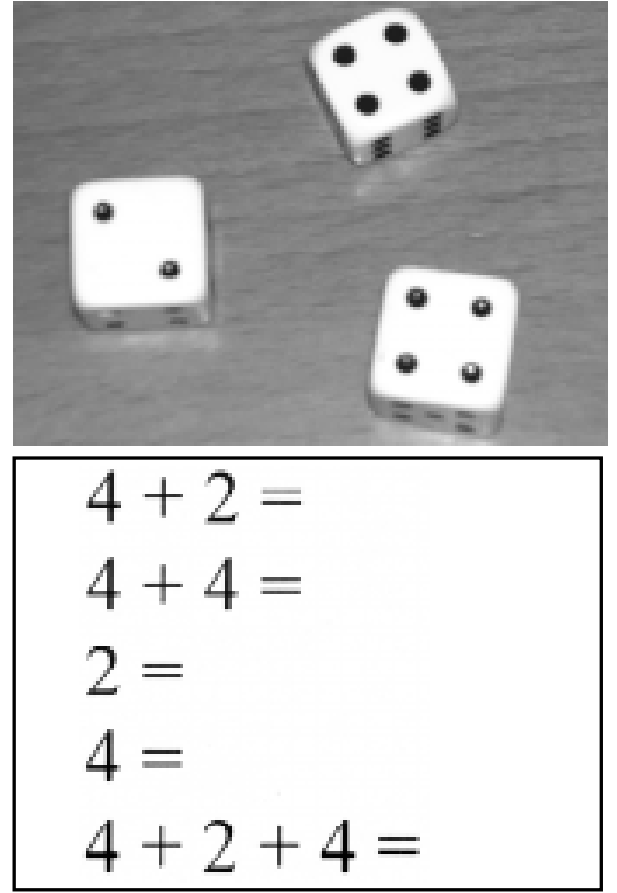




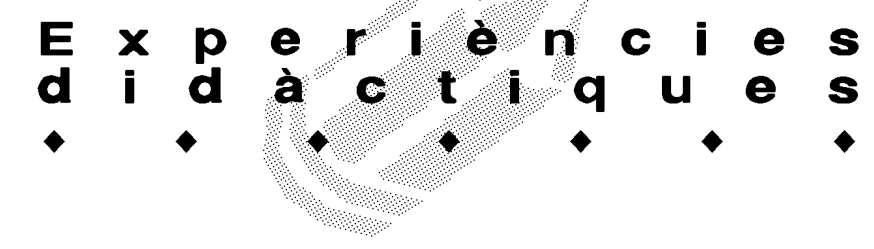

- Nombre de jugadors: Quatre alumnes (o sis). Juguen equips de dues persones.

- Regles: Cada equip col-loca les seves deu cartes ordenades davant seu. Per torns, cada equip llança els tres daus i gira boca terrosa una sola carta; la que correspon:

- A un número indicat per un dels daus.

- A la suma de dos daus.

- A la suma dels tres daus.

En el cas que per tots els números que s'obtenen les cartes corresponents ja estiguin girades, passa el torn al següent equip. Guanya l'equip que primer aconsegueix girar totes les seves cartes.

Els objectius d'aprenentatge -compartits amb els alumnes- amb relació a aquest joc estan orientats a la capacitat de l'alumnat per:

- Sumar dues i tres quantitats correctament.

- Resoldre algunes operacions sense comptar (resposta automatitzada o estratègies de càlcul mental).

- Reconèixer tots els resultats possibles d'una jugada fent combinacions de tres quantitats.

- Descobrir que hi ha resultats que apareixen amb menys freqüència $(10,9,8 \ldots)$ que altres $(5,4,3 \ldots)$.

- Escollir, de tots els resultats possibles, els més convenients tenint en compte la freqüència amb què apareixen.

- Prendre decisions amb el company d'equip.

- Col-laborar amb els companys per organitzar i dur a terme la tasca conjuntament.

(Vegeu Edo, 2003 per a l'explicació dels deu jocs del taller amb els respectius continguts matemàtics, objectius d'aprenentatge i sistemes d'avaluació).

\section{Un dels resultats de la recerca-acció}

Un dels objectius que es va plantejar l'equip era poder respondre si el fet de participar en el taller augmentava les

\begin{tabular}{|c|c|c|c|c|}
\cline { 2 - 5 } \multicolumn{1}{c|}{} & $\begin{array}{c}\text { Mitjana } \\
\text { encerts } \\
\text { grup A }\end{array}$ & $\begin{array}{c}\text { Mitjana } \\
\text { encerts } \\
\text { grup B }\end{array}$ & $\begin{array}{c}\text { Mitjana } \\
\text { encerts } \\
\text { dos grups }\end{array}$ & $\begin{array}{c}\text { Puntuació típica } \\
\text { a partir de les } \\
\text { directes }\end{array}$ \\
\hline $\begin{array}{c}\text { Curs } \\
1990-91\end{array}$ & 6,5 & 6,3 & $\mathbf{6 , 4}$ & Bé $(4,5$ a 6,9) \\
\hline $\begin{array}{c}\text { Curs } \\
1991-92\end{array}$ & 6,4 & 6,8 & $\mathbf{6 , 6}$ & Bé $(4,5$ a 6,9) \\
\hline $\begin{array}{c}\text { Curs } \\
1992-93\end{array}$ & 5,3 & 6,5 & $\mathbf{5 , 9}$ & Bé $(4,5$ a 6,9) \\
\hline $\begin{array}{c}\text { Curs } \\
1993-94\end{array}$ & 5,4 & -- & $\mathbf{5 , 4}$ & Bé $(4,5$ a 6,9) \\
\hline $\begin{array}{c}\text { Curs } \\
\mathbf{1 9 9 4 - 9 5}\end{array}$ & $\mathbf{7 , 6}$ & $\mathbf{7 , 9}$ & $\mathbf{7 , 7}$ & Notable $(\mathbf{7}$ a 9,4) \\
\hline
\end{tabular}

Taula 1. Resultats de la prova de càlcul mental de quatre cursos anteriors i del curs de l'experimentació a 1r de primària.

capacitats de calcular mentalment en els alumnes implicats.

En aquesta escola, al final de cada curs escolar, es realitzen unes proves estandarditzades de càlcul mental; són proves de rapidesa de càlcul en les quals els infants han de resoldre, en un minut, tantes operacions senzilles, de suma i resta, com els sigui possible. L'infant que té més resultats automatitzats o que és capaç d'utilitzar més estratègies de càlcul que de procediments de recompte, obtindrà una puntuació més alta.

En el curs escolar de l'experimentació es va utilitzar la mateixa prova que els quatre anys anteriors, i es van mantenir la resta de sessions de matemàtiques: el programa, la bateria de problemes mentals, la metodologia, etc. Podem inferir, per tant, que els resultats del canvi són deguts a la innovació realitzada en el curs en qüestió.

Les dades (taules 1 i 2 ) de les dues primeres columnes són la mitjana de respostes encertades per infant, durant un minut, en una classe. A la tercera columna hi trobem la mitjana de dos grups d'un mateix curs escolar, també en puntuació directa, és a dir, el nombre d'encerts en un minut. A la darrera columna presentem la puntuació típica obtinguda a partir de les directes, és a dir, la valoració global del curs en relació amb la puntuació resultant d'una mostra representativa d'alumnes de la mateixa edat. El que observem en les dades de les dues taules és que la mitjana de respostes encertades que s'obtenen en el curs de la innovació són les més elevades que mai no s'havien produït en aquesta escola (des que es realitza aquesta prova). Tenint en compte que la puntuació mitjana de la població que utilitza les mateixes proves (obtinguda en una mostra de 466 infants a 1r i de 657 a 2n) és de 5,25 per primer de primària i de 5,32 pels alumnes de segon, el resultat obtingut l'any de l'experimentació és significativament superior. Observem també que és la primera vegada que en tipificar les puntuacions directes s'obté un notable de mitjana per a tots els grup classe implicats. Podem afirmar que en aquesta escola el fet d'haver aplicat

\begin{tabular}{|c|c|c|c|c|}
\cline { 2 - 5 } \multicolumn{1}{c|}{} & $\begin{array}{c}\text { Mitjana } \\
\text { encerts } \\
\text { grup A }\end{array}$ & $\begin{array}{c}\text { Mitjana } \\
\text { encerts } \\
\text { grup B }\end{array}$ & $\begin{array}{c}\text { Mitjana } \\
\text { encerts } \\
\text { dos grups }\end{array}$ & $\begin{array}{c}\text { Puntuació típica } \\
\text { a partir de les } \\
\text { directes }\end{array}$ \\
\hline $\begin{array}{c}\text { Curs } \\
1990-91\end{array}$ & 6,2 & 7,5 & $\mathbf{6 , 8}$ & Notable $(6,5$ a 8,4) \\
\hline $\begin{array}{c}\text { Curs } \\
1991-92\end{array}$ & 6,4 & 5,2 & $\mathbf{5 , 8}$ & Bé $(4,5$ a 6,4) \\
\hline $\begin{array}{c}\text { Curs } \\
1992-93\end{array}$ & 5,3 & 7,0 & $\mathbf{6 , 1}$ & Bé $(4,5$ a 6,4) \\
\hline $\begin{array}{c}\text { Curs } \\
1993-94\end{array}$ & 6,2 & -- & $\mathbf{6 , 2}$ & Bé $(4,5$ a 6,4) \\
\hline $\begin{array}{c}\text { Curs } \\
\mathbf{1 9 9 4 - 9 5}\end{array}$ & $\mathbf{7 , 2}$ & $\mathbf{7 , 0}$ & $\mathbf{7 , 1}$ & Notable $(6,5$ a 8,4) \\
\hline
\end{tabular}

Taula 2. Resultats de la prova de càlcul mental de quatre cursos anteriors i del curs de l'experimentació a 2n de primària. 


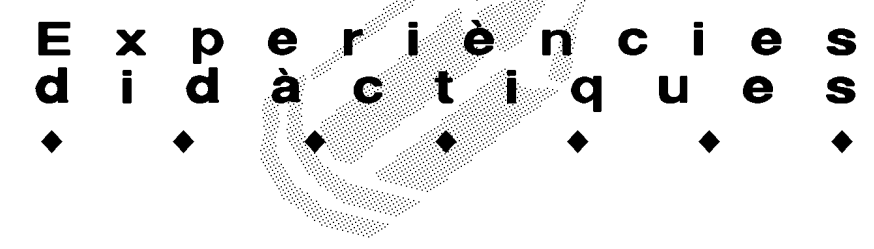

el taller complet, amb els deu jocs i amb totes les directrius didàctiques que conté, augmenta significativament la capacitat dels alumnes implicats de calcular mentalment.

\section{Joc, interacció i construcció de coneixements mate- màtics}

En la segona fase de la recerca interessava estudiar si hi havia evidències de l'augment de la capacitat de cooperar dels alumnes, és a dir, si augmentava la capacitat de donar-se ajudes efectives en el procés d'aprenentatge en un context de joc. Primer vam adonar-nos que l'estudi de l'evolució de les interaccions entre els companys, en un entorn escolar, implica l'estudi de les actuacions dels alumnes, les de la mestra i el contingut de la tasca de forma simultània. Per això la metodologia d'aquesta recerca (EDO, 2002) es va centrar en el model conceptual i metodològic per a l'anàlisi d'alguns mecanismes d'influència educativa que operen en la interactivitat (COLL, COLOMINA, ONRUBIA, i ROCHERA, 1995; COLL i ROCHE$\mathrm{RA}, 2000$ ).

Entenem la influència educativa en termes d'ajuda al procés constructiu que realitza l'alumnat. Centrar-se en la interactivitat implica estudiar l'articulació de les actuacions de la mestra i dels alumnes al voltant d'una tasca i un contingut determinats, al llarg del temps (COLL i altres, op. cit.).

Disposàvem d'enregistraments -vídeo i àudio-de totes les sessions d'un grup de quatre alumnes (dos nens i dues nenes) de segon de primària, durant els quatre primers jocs del taller. De tot l'enregistrament vam escollir dues seqüències didàctiques, concretament la primera amb el joc "Et demano" i la tercera amb "Memòria 12". Es va desestimar la segona seqüència perquè només hi intervenien dos jugadors, i la quarta perquè hi havia massa temps de distància respecte al primer joc. Per tant, vam seleccionar totes les sessions de dos jocs del taller, les quals tenien una durada aproximada de quaranta minuts cadascuna, i es van transcriure per a l'anàlisi.

Dos dels principals objectius que vam plantejar són:

1. Identificar indicadors interpretables com a influència educativa en la interacció mestra-alumnes.

2. Identificar si es produeixen indicadors interpretables com a influència educativa dels alumnes en la interacció entre iguals.

Una recerca d'aquestes característiques és llarga i complexa (per conèixer fases i resultats vegeu Edo i Deulofeu, 2006). A continuació presentem, a grans trets, alguns dels processos i resultats rellevants.

\section{Anàlisi de la influència educativa de la mestra en la in- teracció amb alumnes}

Una part de l'anàlisi per abordar el primer objectiu va consistir a estudiar com eren i com evolucionaven les actua- cions de la mestra al llarg de cada seqüència didàctica. Els resultats d'aquesta part d'anàlisi mostren que la mestra varia el nombre d'intervencions segons la sessió, intervé molt més en les sessions inicials d'un joc i redueix gradualment les seves aportacions, que desapareixen pràcticament del tot a les sessions finals. També vam observar que variava el tipus d'actuació, segons amb qui interactuava (alumnes més o menys autònoms) i segons si era a les sessions inicials, intermèdies o finals. Hi ha actuacions de la mestra que comporten un alt grau de control, com informar, explicar i corregir (que apareixen més a les sessions inicials del joc). Hi ha actuacions de baix grau de control, com demanar identificació i correcció d'errors, reforçar l'actuació autònoma i modelar l'actuació pertinent en el joc (que apareixen majoritàriament a les sessions intermèdies). A les sessions finals pràcticament no intervé.

Vegem ara un exemple d'un fragment del joc "Et demano..." en què la mestra realitza una actuació de baix grau de control i demana que els alumnes identifiquin i corregeixin un error, en lloc de corregir-lo ella.

El joc consisteix a repartir totes les cartes (el mateix nombre) entre els jugadors. A continuació cada jugador fa parelles de cartes que sumades donin 10 i les descarta en un munt particular de cartes guanyades. Tot seguit el jugador que té el torn demana, al company que vulgui, una carta que sumi $10 \mathrm{amb}$ una de pròpia i les descarta. Continua l'acció fins que algun jugador no té la carta sollicitada. Passa el torn a aquest últim jugador. S'acaba la partida quan totes les cartes han estat aparellades. Guanya el jugador que ha recollit més cartes.

Exemple 1: Han jugat una partida d'aquest joc tres persones (la Maria, la Mònica i la mestra). La baralla conté 36 cartes. S'ha acabat una partida. La mestra demana a les alumnes que dedueixin el guanyador (qui té més cartes al seu munt particular) i es retira. Les alumnes compten les cartes que ha recollit cadascuna de les tres jugadores. Reapareix la mestra.

\section{Transcripció}

Mestra: Què? Qui ha guanyat?

Maria: Empatem a dotze, ella i jo (assenyalant la Mònica i a ella mateixa), $i$ tu, onze (assenyala la mestra).

Mestra: Segur que pot ser? Jo onze Demana reflexió i vosaltres dotze?

Maria i Mònica: Sí. Actuació Demana informació Respon a petició informació

Mestra: Al principi de tot de tot (quan hem repartit les cartes per jugar), quantes en teníem cadas-

Cometen error

Demana detecció $\mathrm{i}$ correcció error pensa.

Un dels principals resultats, vinculat a la influència educativa de la mestra en els alumnes, és: 


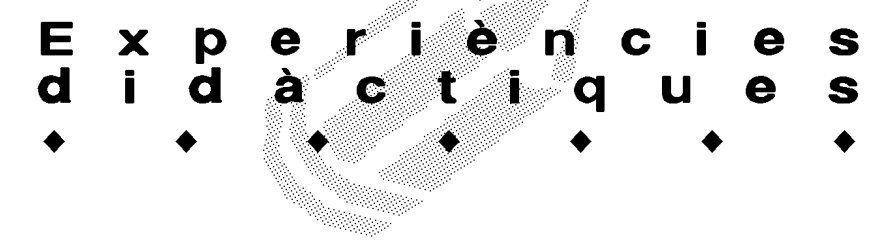

- La mestra cedeix i traspassa progressivament el control de la tasca als alumnes i redueix el nombre i el grau de les ajudes que realitza.

- Entre les estratègies utilitzades per a la cessió i el traspàs del control, la mestra implica els alumnes en el procés de detecció i correcció d'errors i dificultats pròpies i dels companys, preguntant directament a diferents alumnes i convidant a participar, però sense corregir els errors.

\section{Anàlisi de la influència educativa en la interacció entre iguals}

Per estudiar la possible influència educativa dels alumnes en la interacció entre iguals vam escollir (entre altres), de les dades transcrites, els fragments que s'iniciaven amb un error, una manifestació de dificultat o una demanda explícita d'un alumne, sempre en relació amb un contingut matemàtic, de càlcul o d'estratègia. Vam analitzar aquests fragments i vam estudiar dos aspectes:

1. Si intervenia la mestra o el gestionaven els alumnes sols.

2. Si l'error o dificultat inicial es resolia.

Vegem ara un exemple d'un fragment que s'inicia amb una manifestació de dificultat d'una alumna. El contingut matemàtic té a veure amb l'estratègia de joc, hi intervenen només alumnes i la dificultat inicial es resol.

Exemple 2:

Juguen tres persones (la Maria, la Mònica i la mestra) al joc "Et demano...". L'acció que es realitza consisteix a demanar a un company una carta que sumi 10 amb una de pròpia i a descartar-les. Té el torn la Maria, a qui li queden dues cartes. En una jugada anterior la Maria havia sol-licitat a la seva companya Mònica, sense èxit, una carta numerada amb un 1.

\section{Transcripció}

Actuació

Mestra: Què? Qui ha guanyat?

Maria: (Mira les seves cartes, fa

Manifesta dificultat

soroll amb la boca, les torna a

mirar, passa el temps) Ai, Déu

meu, estic perduda!

Mònica: (Es dirigeix a la Maria) Ah! Maria, si abans m'ho has preguntat a mi. Qui ho tindrà?

Maria: (Reaccionant de seguida i dirigint-se al tercer jugador)

Tens un 1?

A la taula 3 es mostren les dades d'aquesta fase d'anàlisi.

Les dades de la taula 3 mostren que en el primer joc la mestra intervé, proporcionalment, en moltes de les oca-

Ajuda ajustada

Corregeix i resol sions en què s'intenta resoldre un error, dificultat o demanda d'una alumna. De les deu ocasions que els alumnes s'enfronten en solitari a un d'aquests fragments, només quatre casos es resolen, és a dir, només el $40 \%$ dels intents de gestionar un error, mostra de dificultat o demanda d'un company, sense el suport de la mestra, se solucionen positivament. Pel que fa al segon joc, podem observar que la intervenció de la mestra en la gestió d'aquests fragments proporcionalment s'ha reduït molt. Els alumnes en solitari han quadruplicat els intents respecte al primer joc. Dels 43 fragments gestionats pels alumnes, només se'n resolen 32 , és a dir, al voltant del $75 \%$ dels intents finalitzen positivament.

Els resultats que es mostren indiquen l'augment de la capacitat d'exercir una influència educativa entre els companys. Un dels principals resultats de la recerca, vinculat al de la influència educativa dels alumnes en la interacció entre iguals, és:

- L'evidència de l'augment de la capacitat dels alumnes per exercir ajudes mútues i de la capacitat d'acceptar i utilitzar aquestes ajudes en el procés d'aprenentatge de continguts matemàtics inclosos en el joc.

- Les ajudes són molt reduïdes i poc efectives en el joc inicial, i nombroses i efectives en el segon joc.

\section{Implicacions didàctiques}

Els resultats de la recerca avalen les recomanacions didàctiques que indiquen que alguns jocs, ben utilitzats, creen a l'escola un context proper a una bona pràctica. Com s'ha mostrat, en aquest cas a cicle inicial, afavoreixen l'aprenentatge de continguts matemàtics relacionats amb la comprensió del nombre i la rapidesa de càlcul mental. Podem concloure també que, si la gestió de l'activitat es condueix des d'un marc constructivista, pot afavorir que la mestra cedeixi i traspassi el control de la tasca als alumnes, els quals augmenten la capacitat de donar el suport necessari al seu aprenentatge. Per tant, podem dir que el context de joc és adequat per aprendre matemàtiques, per ser més autònoms i per cooperar, elements que incideixen positivament en el desenvolupament cognitiu, personal i social de l'alumnat.

\begin{tabular}{|l|c|c|}
\hline $\begin{array}{l}\text { Fragments dinteracció que sini- } \\
\text { cien amb un error, una mani- } \\
\text { festació de dificultat o una de- } \\
\text { manda. }\end{array}$ & $\begin{array}{l}\text { fragments del } \\
\text { primer joc }\end{array}$ & $\begin{array}{l}\text { fragments del } \\
\text { segon joc }\end{array}$ \\
\hline $\begin{array}{l}\text { Hi intervenen els alumnes i } \\
\text { la mestra. }\end{array}$ & 28 & 18 \\
\hline $\begin{array}{l}\text { Hi intervenen els alumnes } \\
\text { sols. }\end{array}$ & 10 & 43 \\
\hline
\end{tabular}

Taula 3. Resultats de la gestió de fragments d'interacció. 


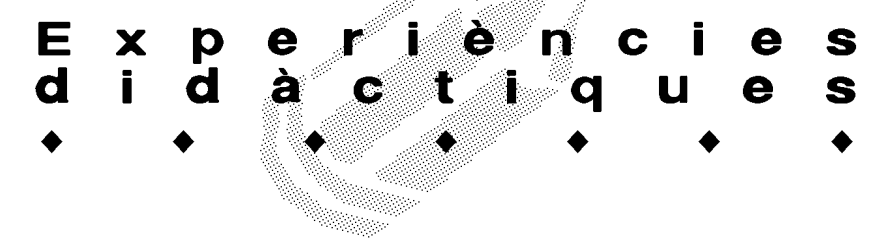

\section{Referències bibliogràfiques}

BELMONTE, J. M. "El juego en la educación infantil". Dins CHAMORRO, M. Didáctica de las matemáticas. Edit. Pearson. Madrid. 2006. Pàg. 384-407.

BISHOP, A. J. Enculturación matemática, la educación matemática desde una perspectiva cultural. Edit. Paidós. Barcelona. 1999.

BRUNER, J. "Vygotsky: a historical and conceptual perspective". Dins WERTSCH, J. V. (Ed.) Culture, Communication and Cognition: Vigotskian perspectives. Edit. Cambridge University Press. Cambridge. 1985. Pàg. 21-34.

COLL, C., COLOMINA, R., ONRUBIA, J. i ROCHERA, M. J. "Actividad conjunta y habla: una aproximación al estudio de los mecanismos de influencia educativa". Dins FERNÁNDEZ BERROCAL, P. i MELERO, M. A. (Ed.). La interacción social en contextos educativos. Edit. Siglo XXI. Madrid. 1995.

COLL, C. i ROCHERA, M. J. Actividad conjunta y traspaso del control en tres secuencias didácticas sobre los primeros números de la serie natural. «Infancia y Aprendizaje», 92 (2000) 109-130.

COSTA, A., EDO, M., FONT, M. i FORRELLAD, H. Disseny, aplicació $i$ avaluació d'un taller de jocs matemàtics al cicle inicial de primària. «Perspectiva Escolar», 226 (1998) 60-67.

COCKCROFT, W. H. (Ed.), Las matemáticas si cuentan. Informe Cockcroft. Edit. MEC. Madrid. 1985.

DESJARDINS-ROYON, C. "Jeux de société apprentissages numériques et pédagogie interactive au cours préparatoire". Dins HARDY, M., PLATONE, F., STAMBAK, M. (Eds.). Naissance d'une pédagogie interactive. Edit. Cresas, ESF/INRP. París. 1991. Pàg. 87-107.

EDO, M. Taller de jocs al cicle inicial: Disseny, experimentació i avaluació d'una situació didàctica per a la construcció conjunta de coneixements matemàtics. Treball de recerca de doctorat en Didàctica de les Ciències i les Matemàtiques. Dpt. de Didàctica de les Matemàtiques i les Ciències Experimentals. Universitat Autònoma de Barcelona. Barcelona. 1996.

EDO, M. Juegos y matemáticas. Una experiencia en el ciclo inicial de primaria. «UNO, revista de Didáctica de las matemáticas», 18 (1998) 21-37.

EDO, M. Jocs, interacció i construcció de coneixements matemàtics. Tesi doctoral. Universitat Autònoma de Barcelona. Bellaterra. 2002.

EDO, M. "Juegos matemáticos. Documentación para el taller. Desarrollo curricular. Estrategias e instrumentos". Dins TOMÁS, C. i CASAS, M. (Eds.). Educación Primaria. Orientaciones y Recursos. Edit. CISSPRAXIS. Barcelona. 2003. CD-Rom. 59 Pàg.

EDO, M. "Taller de juegos y matemáticas en el ciclo inicial de primaria, Desarrollo curricular. Estrategias e instrumentos". Dins TOMÁS, C. i CASAS, M. (Eds.), Educación Primaria. Orientaciones y Recursos. Edit. CISSPRAXIS. Barcelona. 2004. CD-Rom. 13 Pàg.

EDO, M. i DEULOFEU, J. Investigación sobre juegos, interacción y construcción de conocimientos matemáticos. «Enseñanza de las Ciencias», 24,2 (2006) 257-268.

EDO, M. i MASOLIVER, C. Una tienda en clase. Creación y análisis de un contexto para aprendizajes matemáticos. «UNO, revista de Didáctica de las matemáticas», 47 (2008) 20-36.

ELKONIN, D. B. Psicología del juego. Edit. Pablo del Río. Madrid. 1980.

GARAIGORDOBIL, M. Las aportaciones de la teoría del egocentrismo de Piaget a la investigación del juego infantil. «Revista Infancia», 91 (2005) 4-9.

GENERALITAT de CATALUNYA. Currículum de matemàtiques per a l'Educació Primària. Annex al decret 142/2007 pel qual s'estableix l'ordenació dels ensenyaments de l'educació primària. (Pàg. 21822) DOGC 4915 - 29/06/2007.

KAMII, C. El niño reinventa la aritmética, Implicaciones de la teoría de Piaget. Edit. Visor. Madrid. 1988.

KAMII, C. Reinventando la aritmética II. Edit. Visor. Madrid. 1992.

KAMII, C. i DE VRIES, R. Juegos colectivos en la primera enseñanza: Implicaciones de la teoría de Piaget. Edit. Visor. Madrid. 1980.

KAMII, C. i KATO, Y. Fostering the Development of LogicMathematical Thinking in a Card Game at Ages 5-6. «Early Education \& Development», 16,3 (2005) 367-383.

KAMII, C. RUMMELSBURG, J. i KARI, A. Teaching arithmetic to low-performing, low-SES first grades. «Mathematical Behaviour», 24, (2005) 39-50.

NATIONAL COUNCIL OF TEACHERS OF MATHEMATICS. Principles and standards for school mathematics. Edit. National Council of Teachers of Mathematics. Reston. 2000.

ORTEGA, R. Un marco conceptual para la interpretación psicológica del juego infantil. «Infancia y aprendizaje», 55 (1991) 87102.

PIAGET, J. La formación del símbolo en el niño. Edit. Fondo de Cultura Económica. México. 1986.

TOPPING, K. J. i BAMFORD, J. Parental involvement and Peer Tutoring in mathematics and Science: developing Paired Math into paired Science. Edit. David Fulton Publishers. London. 1998.

TOPPING, K. J., CAMPBELL, J., DOUGLAS, W. i SMITH, A. Cross-Age Peer Tutoring in Mathematics with Seven- and 11year-olds: Influence on Mathematical Vocabulary, Strategic Dialogue and Self-Concept. «Educational Research», 45, 3 (2003) 287-308.

VAN OERS, B. Semiotic activity of young children in play: the construction and use of schematic representations. «European Early Childhood Education Research Journal», 2, 1 (1994) 19-34.

VAN OERS, B. Teaching Opportunities in Ply. Dins HEDEGAARD, M. i LOMPSCHER, J. (Eds.). Learning Activity and Development. Edit. Aarhus University Press. Oxford. 1999. Pàg. 268-289.

VAN OERS, B. Learning resources in the context of play. Promoting effective learning in early childhood. «European Early Childhood Education Journal», 11,1 (2003) 7-26.

VYGOTSKI, L. "El papel del juego en el desarrollo del niño". Dins COLE, M., JOHN-STEINER, V., SCRIBNER, S. i SOUBERMAN, E. (Eds.). El desarrollo de los procesos psicológicos superiores. Edit. Crítica. Barcelona. 2003. Pàg. 141-158. 